BMJ Open

Diabetes

Research

\& Care

\section{Periconception glycemic control and congenital anomalies in women with pregestational diabetes}

To cite: Dude AM, Badreldin N, Schieler A, et al. Periconception glycemic control and congenital anomalies in women with pregestational diabetes. BMJ Open Diab Res Care 2021;9:e001966. doi:10.1136/ bmjdrc-2020-001966

This paper was previously presented at the Society for Maternal-Fetal Medicine Annual Meeting, Las Vegas, NV, February 13-16, 2019.

Received 23 October 2020 Revised 16 March 2021 Accepted 21 March 2021
Check for updates

(C) Author(s) (or their employer(s)) 2021. Re-use permitted under CC BY-NC. No commercial re-use. See rights and permissions. Published by BMJ.

${ }^{1}$ Department of Obstetrics \& Gynecology, University of Chicago Pritzker School of Medicine, Chicago, Illinois, USA ${ }^{2}$ Department of Obstetrics \& Gynecology, Northwestern University Feinberg School of Medicine, Chicago, Illinois, USA

Correspondence to

Dr Annie M Dude;

adude@bsd.uchicago.edu

\section{ABSTRACT}

Introduction To assess the relationship between periconception glycemic control and congenital anomalies in a contemporary, diverse population of women with pregestational diabetes.

Research design and methods This is a retrospective cohort study of all pregnant women with pregestational diabetes at a single institution (2003-2017) in the USA. The primary outcome was frequency of major or minor congenital anomalies. Glycemic control was assessed by periconception glycosylated hemoglobin $(\mathrm{HbA} 1 \mathrm{c})$. The association of periconception $\mathrm{HbA} 1 \mathrm{c}$ with pregnancy outcomes was assessed using bivariable and multivariable analyses.

Results Our sample included 351 women, of which $63.8 \%$ had type 2 diabetes. Our study cohort is racially and ethnically diverse, with approximately equal numbers of women identifying as white non-Hispanic, black nonHispanic and Hispanic, with $3.4 \%$ identifying as Asian. Of these 351 women, $52(14.8 \%)$ had a fetus with a congenital anomaly, of whom the majority $(n=43)$ had a major anomaly. Over half (51.1\%) of all major anomalies were cardiovascular. Compared with the group with the best glycemic control ( $\mathrm{HbA} 1 \mathrm{C} \leq 7.4 \%)$, which had an anomaly frequency of $10.2 \%$, the frequency of congenital anomalies increased significantly with each category of worsening glycemic control (HbA1c 7.5\%-9.4\%: 20.6\%, adjusted OR (aOR) 2.35, 95\% confidence interval (CI) 1.08 to 5.13 ; $\mathrm{HbA} 1 \mathrm{c} 9.5 \%$ to $11.4 \%$ : $25.8 \%$, aOR $2.86,95 \% \mathrm{Cl}$ 1.08 to 7.59 ; $\mathrm{HbA} 1 \mathrm{C} \geq 11.5 \%: 37.5 \%$, aOR $7.66,95 \% \mathrm{Cl}$ 2.27 to 25.9$)$.

Conclusion In a diverse cohort of women with pregestational diabetes, higher periconception $\mathrm{HbA} 1 \mathrm{c}$, especially $\mathrm{HbA1C}>9.5$, was significantly associated with major congenital fetal anomalies. Our study sample is reflective of the current population of pregnant women with diabetes, including women with type 2 diabetes and from racial and ethnic minorities.

\section{INTRODUCTION}

Pregestational diabetes affects approximately $1 \%$ of pregnancies in the USA, ${ }^{1}$ and its prevalence is increasing. ${ }^{2}$ Women with pregestational diabetes are at greater risk of spontaneous abortion, ${ }^{3}$ stillbirth, ${ }^{4}$ macrosomia ${ }^{5}$ and congenital anomalies. ${ }^{6}$ Past research indicates that the risk of these outcomes increases with worsening maternal glycemic control. ${ }^{7}$

\section{Significance of this study}

What is already known about this subject?

- Congenital anomalies are more common among pregnant women with diabetes who have poor periconceptional glycemic control. Much of the original data on this topic, however, focuses on white women with type 1 diabetes, although more recent literature incorporates more women with type 2 diabetes. The characteristics of pregnant women with pregestational diabetes have changed significantly over time, with non-white women with type 2 diabetes now comprising the majority.

\section{What are the new findings?}

- In a diverse cohort of women with pregestational diabetes that is more reflective of the contemporary population of women with diabetes in pregnancy, higher periconception glycosylated hemoglobin (HbA1c), especially $\mathrm{HbA1c}>9.5 \%$, was significantly associated with major and minor congenital fetal anomalies.

How might these results change the focus of research or clinical practice?

- These results emphasize the importance of periconceptional glycemic control among women with diabetes of reproductive age.

Congenital anomalies are especially known to be associated with poor glycemic control in women with diabetes. ${ }^{8}$ Numerous studies have demonstrated rates of fetal anomalies ranging from $4.5 \%$ among women with well-controlled diabetes to as high as $30 \%-40 \%$ among women with poor glycemic control. ${ }^{710}$ The background risk of congenital anomalies in the general population, in contrast, is $2 \%-4 \% .^{7911}$ Cardiac and neural tube anomalies, which often require surgical correction and cause significant neonatal morbidity and mortality, are especially common among women with diabetes. ${ }^{1213}$

Much of the original literature, however, regarding the increased risk of congenital anomalies in women with diabetes comes from the 1980 s to $1990 \mathrm{~s}^{79}$ These older studies disproportionately included non-Hispanic 
white women with type 1 diabetes, as these women comprised the majority of those entering pregnancy with diabetes during that era. The majority of women currently entering pregnancy with diabetes, however, have type 2 diabetes,${ }^{14}$ which disproportionately affects individuals from racial and ethnic minorities in the US population. ${ }^{15}$ Although previous research indicates that women with type 2 , as opposed to type 1 , diabetes have similar risks of congenital anomalies, these largely used administrative rather than clinical data and were mainly performed outside the USA. ${ }^{10}$ 16-21 Individuals with diabetes in the USA are also more likely to be obese, which may compound the risks incurred by hyperglycemia alone. In this paper, we quantify the risks of congenital anomalies among women with pregestational diabetes in a diverse cohort that is more reflective of the contemporary pregnant population in the USA.

\section{MATERIALS AND METHODS}

This is a retrospective cohort study of all pregnant patients with pregestational diabetes who received care at Northwestern Memorial Hospital between 1 January 2003 and 1 January 2017. At this institution, located in Chicago, Illinois, over 11000 individuals give birth each year, and a long-standing diabetes and pregnancy program has provided comprehensive care to a large referral population of individuals with pregestational or gestational diabetes. For this study, pregnant women with any type of pregestational diabetes were identified by querying the institutional electronic medical record. Records queried included those from deliveries, ultrasound, pathology and any other interaction with this healthcare system, and thus women whose pregnancies did not end in a live birth were able to be captured. Women were excluded if, on further review, they were found to have gestational diabetes, multifetal gestation or a known fetal chromosomal abnormality on diagnostic testing. Women were also excluded if they had incomplete data on periconception glycosylated hemoglobin (HbAlc), defined as no HbAlc value measured during the 3 months before or after the estimated time of conception. Pregnancy outcomes were identified and classified as either first trimester induced abortion, spontaneous pregnancy loss prior to 20 weeks' gestation, intrauterine fetal demise at 20 weeks' gestation or greater or live birth. Women were ultimately included if they had a pregnancy that lasted beyond 20 weeks' gestation regardless of pregnancy outcome. For women who had more than one pregnancy that lasted beyond 20 weeks' duration, only data from the first pregnancy during the study time period were used.

Information regarding congenital anomalies was collected through review of ultrasound reports, autopsy records and neonatal physical examinations. Major and minor anomalies were defined in concordance with the European Surveillance of Congenital Anomalies (EUROCAT) classifications. ${ }^{22}$ Major anomalies were defined as those that have medical and/or social implications, many of which often require surgical repair or are life threatening, such as complex cardiac defects or neural tube defects. Minor anomalies were defined as those having only cosmetic significance or that presented only minor functional issues, such as extra digits or mild pelviectasis. These definitions were in accordance with previous studies. ${ }^{23}$ Anomalies were then further classified according to affected organ system. Fetuses were categorized as having multiple anomalies if more than one organ system was affected. When available, information regarding diagnostic genetic testing was obtained from results of amniocentesis or chorionic villi sampling, or in the case of intrauterine fetal demise (IUFD) or pregnancy termination from placental chromosomal analysis or fetal chromosomes.

Glycemic control, as measured by HbAlc, was modeled two ways. First, glycemic control was modeled as a continuous variable. Second, HbA1c was modeled as a categorical variable. We assigned women to one of four glycemic control groups: $\leq 7.4 \%$ ( $\leq 57$ millimoles $/$ mole $(\mathrm{mmol} / \mathrm{mol})), 7.5 \%-9.4 \% \quad(58-79 \mathrm{mmol} / \mathrm{mol}), 9.5 \%-$ $11.4 \%(80-101 \mathrm{mmol} / \mathrm{mol})$ and $\geq 11.5 \% \quad(\geq 102 \mathrm{mmol} /$ mol). These values are similar to those used in prior studies. $^{724}$ This latter method may be less sensitive to violations of assumed linearity between $\mathrm{HbAlc}$ and outcome. For multivariable models, we decided a priori to include several potential confounders known to be associated with increased risk of congenital anomalies, including age, body mass index (BMI), parity (nulliparous vs multiparous), insurance status (public vs private) and smoking status (any vs none). As the sample size was fixed, no power calculations were performed.

Student's t-tests, analysis of variance or Wilcoxon rank-sum tests were used for bivariable analyses with continuous variables, and $\chi^{2}$ and Fisher's exact tests were used for bivariable analyses with categorical variables. Multivariable logistic regression was used to control for potential confounders. All hypothesis tests were two tailed, and a probability value of 0.05 was used to determine statistical significance. All analyses were carried out in STATA (V.15.0, StataCorp, College Station, Texas, USA).

\section{RESULTS}

A total of 443 pregnant women with pregestational diabetes and an HbA1c within 3 months (either before or after) of the start of the observed pregnancy were initially identified. We excluded 20 women with a multifetal gestation and 5 women with a diagnosis of fetal chromosomal abnormalities. A further 66 women either underwent pregnancy termination $(\mathrm{n}=19)$ or had a spontaneous pregnancy loss prior to 20 weeks' gestation $(\mathrm{n}=47)$. Women with a higher HbA1c were more likely to undergo pregnancy termination $(\mathrm{p}=0.04)$. The final sample size for analysis included 351 women.

This study population was racially and ethnically diverse, with $29.3 \%$ of women identifying as white non-Hispanic, 
Table 1 Maternal characteristics by periconception glycosylated hemoglobin

\begin{tabular}{|c|c|c|c|c|c|c|}
\hline Variable & $\begin{array}{l}\text { Overall } \\
\text { sample } \\
(\mathrm{N}=351)\end{array}$ & $\begin{array}{l}\leq 7.4 \% \\
\leq 57 \mathrm{mmol} / \mathrm{mol} \\
(n=236)\end{array}$ & $\begin{array}{l}7.5 \%-9.4 \% \\
58-79 \mathrm{mmol} / \mathrm{mol} \\
(\mathrm{n}=68)\end{array}$ & $\begin{array}{l}9.5 \%-11.4 \% \\
80-101 \mathrm{mmol} / \mathrm{mol} \\
(\mathrm{n}=31)\end{array}$ & $\begin{array}{l}\geq 11.5 \% \\
\geq 102 \mathrm{mmol} / \mathrm{mol} \\
(\mathrm{n}=16)\end{array}$ & P value* \\
\hline Maternal age (years) & $32.3 \pm 5.7 \dagger$ & $32.3 \pm 5.9$ & $32.0 \pm 5.7$ & $32.3 \pm 5.5$ & $33.4 \pm 4.1$ & 0.84 \\
\hline Nulliparous & $175(49.9)$ & $119(50.4)$ & $33(48.5)$ & $15(48.4)$ & $8(50.0)$ & 0.99 \\
\hline Body mass index $\left(\mathrm{kg} / \mathrm{m}^{2}\right)$ & $34.7 \pm 9.1$ & $34.3 \pm 9.4$ & $36.1 \pm 8.6$ & $34.6 \pm 8.0$ & $35.5 \pm 9.4$ & 0.57 \\
\hline Race/ethnicity & & & & & & 0.01 \\
\hline White non-Hispanic & $103(29.3)$ & 73 (30.9) & $12(17.7)$ & 10 (32.3) & $8(50.0)$ & \\
\hline Black non-Hispanic & 98 (27.9) & $54(22.8)$ & $34(50.0)$ & $8(25.8)$ & $2(12.5)$ & \\
\hline Hispanic & $98(27.9)$ & $71(30.1)$ & $14(20.6)$ & $8(25.8)$ & $5(31.3)$ & \\
\hline Asian & $12(3.4)$ & $10(4.2)$ & $1(1.5)$ & $1(3.2)$ & $0(0.0)$ & \\
\hline Other & $40(11.4)$ & 28 (11.9) & 7 (10.3) & $4(12.9)$ & $1(6.3)$ & \\
\hline Public insurance & $211(70.1)$ & $151(75.9)$ & $36(58.1)$ & $18(66.7)$ & $6(46.2)$ & 0.01 \\
\hline Smoking & $89(26.0)$ & $58(25.2)$ & $15(22.4)$ & $10(34.5)$ & $6(37.5)$ & 0.44 \\
\hline Diabetes type & & & & & & 0.34 \\
\hline Type 1 & $127(36.2)$ & $92(39.0)$ & $22(32.4)$ & 10 (32.3) & $3(18.8)$ & \\
\hline Type 2 & $224(63.8)$ & $144(61.0)$ & $46(67.7)$ & $21(67.7)$ & $13(81.3)$ & \\
\hline
\end{tabular}

${ }^{*} \mathrm{P}$ value is for analysis of variance, $\chi^{2}$ or Fisher's exact tests.

$\dagger$ Data presented as mean \pm SD for continuous variables and $n(\%)$ for categorical variables.

$27.9 \%$ identifying as black non-Hispanic, $27.9 \%$ identifying as Hispanic and $3.4 \%$ identifying as Asian. Seventy per cent of women were publicly insured. Women with type 2 diabetes comprised the majority $(63.8 \%)$ of the cohort (table 1). Demographic characteristics largely did not differ by HbAlc, with the exception of race and insurance status (table 1 ). There were no differences in proportion of type 1 versus type 2 diabetes by HbAlc $(\mathrm{p}=0.34)$.

Overall, $14.8 \%$ of women had any fetal anomaly $(n=52)$, and $12.3 \%(n=43)$ had a major fetal anomaly (table 2). Of the anomalies identified, 43 were classified as major and 13 as minor; four fetuses had both major and minor anomalies. Anomalies were predominantly cardiac, with 22 major $(51.2 \%)$ and 2 minor $(15.4 \%)$ cardiac anomalies. On bivariable analysis, higher periconception $\mathrm{HbA1c}$ was significantly associated with any anomaly $(p=0.002)$, as well as major $(p=0.002)$, but not minor $(p=0.38)$, anomalies. The median HbAlc was greater for those with anomalies than those without $(8.4 \%(68 \mathrm{mmol} / \mathrm{mol})$ vs $7.1 \%$ (54 mmol $/ \mathrm{mol}), \mathrm{p}<0.001)$.

When controlling for potential confounding factors (table 3), increasing HbAlc remained associated with both any anomaly (adjusted OR $(\mathrm{aOR})=2.35$, 95\% CI 1.08 to 5.13 for HbAlc 7.5-9.4 (58-79 mmol $/ \mathrm{mol}$ ); $\mathrm{aOR}=2.86,95 \%$ CI 1.08 to 7.59 for HbA1c $9.5-11.4$ (80-101 mmol/mol); aOR 7.66, 95\% CI 2.27 to 25.9 for HbAlc $\geq 11.5(\geq 102 \mathrm{mmol} / \mathrm{mol}))$ and major anomalies (aOR 2.35, 95\% CI 1.02 to 5.44 for HbA1c 7.5-9.4 (58-79 mmol $/ \mathrm{mol})$; aOR $3.17,95 \%$ CI 1.11 to 9.06 for HbA1c 9.5-11.4 (80-101 mmol/mol); aOR 7.75, 95\% CI 2.17 to 27.7 for $\mathrm{HbA1c} \geq 11.5(\geq 102 \mathrm{mmol} / \mathrm{mol}))$. There was no significant association between HbA1c group and minor anomalies.

\section{DISCUSSION}

Pregestational diabetes is increasingly a comorbidity of pregnancy. ${ }^{25}$ This study provides further evidence for a strong association between poor glycemic control and increased risk of congenital anomalies among women with pregestational diabetes, using a cohort of racially and ethnically diverse women more representative of the current obstetric population in the USA than seen in prior studies, which largely focus on women with type 1 diabetes ${ }^{726-28}$ or were performed elsewhere, ${ }^{10}$ 16-21 mostly in European countries. Odds of an anomaly were especially high among the groups with the worst glycemic control (HbAlc $\geq 11.5 \%$ or $\geq 102 \mathrm{mmol} / \mathrm{mol}$ ), a finding consistent with prior studies. ${ }^{24} 27$ Among the group with the worst glycemic control, over one-third of women had at least a minor anomaly, although this is a small group. Similar to the findings of Tinker et $a l,{ }^{12}$ the most common class of defects we found were cardiac defects. Similarly to Eriksen et $a l,{ }^{10}$ however, we found a higher rate of congenital anomalies than the background rate even among women with the best glucose control.

One important implication of this finding is that care for women with pregestational diabetes must occur prior to conception. The American Diabetes Association (ADA) recommends that all women of childbearing age with diabetes receive developmentally appropriate preconception education from the onset of puberty about the risks of malformations associated with unplanned pregnancies during times of poor glycemic control, that preconception 
Table 2 Fetal anomalies by periconception HbA1c

\begin{tabular}{|c|c|c|c|c|c|c|}
\hline Variable & $\begin{array}{l}\text { Overall } \\
\text { sample } \\
(\mathrm{N}=351)\end{array}$ & $\begin{array}{l}\leq 7.4 \% \\
\leq 57 \mathrm{mmol} / \mathrm{mol} \\
(\mathrm{n}=236)\end{array}$ & $\begin{array}{l}7.5 \%-9.4 \% \\
58-79 \mathrm{mmol} / \mathrm{mol} \\
(\mathrm{n}=68)\end{array}$ & $\begin{array}{l}9.5 \%-11.4 \% \\
80-101 \mathrm{mmol} / \mathrm{mol} \\
(\mathrm{n}=31)\end{array}$ & $\begin{array}{l}\geq 11.5 \% \\
\geq 102 \mathrm{mmol} / \mathrm{mol} \\
(n=16)\end{array}$ & P value* \\
\hline Any anomaly & $52(14.8) \dagger$ & 24 (10.2) & 14 (20.6) & $8(25.8)$ & $6(37.5)$ & 0.002 \\
\hline Minor anomaly & $13(3.8)$ & $7(2.6)$ & $3(7.6)$ & $2(6.7)$ & $1(16.7)$ & 0.38 \\
\hline Cardiovascular & 2 & 1 & 1 & 0 & 0 & \\
\hline Musculoskeletal & 3 & 1 & 1 & 1 & 0 & \\
\hline GU & 4 & 2 & 1 & 1 & 0 & \\
\hline ENT & 2 & 2 & 0 & 0 & 0 & \\
\hline Multiple & 1 & 1 & 0 & 0 & 0 & \\
\hline Dermatologic & 1 & 0 & 0 & 0 & 1 & \\
\hline Major anomaly & $43(12.3)$ & $19(8.1)$ & $12(17.7)$ & $7(22.6)$ & $5(31.3)$ & 0.002 \\
\hline Cardiovascular & 22 & 8 & 8 & 2 & 4 & \\
\hline Musculoskeletal/limb & 3 & 1 & 1 & 1 & 0 & \\
\hline GU/renal & 4 & 2 & 1 & 0 & 1 & \\
\hline CNS & 4 & 3 & 0 & 1 & 0 & \\
\hline Gl & 0 & 0 & 0 & 0 & 0 & \\
\hline ENT/face & 1 & 0 & 1 & 0 & 0 & \\
\hline Multiple & 8 & 5 & 1 & 2 & 0 & \\
\hline Dermatologic & 1 & 0 & 0 & 1 & 0 & \\
\hline
\end{tabular}

${ }^{*} \mathrm{P}$ values are for $\chi^{2}$ or Fisher's exact tests.

†Data presented as $\mathrm{n}(\%)$, except for specific organ subgroups of anomalies, which are presented as $\mathrm{n}$ only.

CNS, central nervous system; ENT, ear, nose and throat; Gl, gastrointestinal; GU, genitourinary; HbA1c, glycosylated hemoglobin.

HbAlc should ideally be $<6.5 \%(<48 \mathrm{mmol} / \mathrm{mol})$ and also be advised on the use of contraception. ${ }^{29}$ Adequate preconception care in conjunction with counseling has been proven to reduce birth defects among women with diabetes. ${ }^{30}$ Yet, in recent studies, as few as $4 \%$ of women with pregestational diabetes received this preconception counseling. ${ }^{6}$

Similarly, despite the ADA recommendation that all women with diabetes receive counseling regarding contraception, women with diabetes are often more likely to have an unintended pregnancy and less likely to receive contraception counseling and prescriptions than women without chronic disease. ${ }^{31} 32$ Women with diabetes who experience unintended pregnancies are less likely to have optimal glucose control, ${ }^{33}$ are less likely to recognize that they are pregnant or to initiate prenatal care until at least the second trimester, ${ }^{34}$ well past the point in pregnancy after which most birth defects have developed. Improving counseling about reproductive planning and access to contraception for women with diabetes may help reduce congenital anomalies among this group.

More generally, preconception care for all women could improve outcomes for women with diabetes, as approximately $0.5 \%$ of all US women of reproductive age are estimated to have undiagnosed diabetes, ${ }^{35}$ especially women from racial and ethnic minorities. ${ }^{36}$ One particularly important population of women with pregestational

Table 3 Periconception $\mathrm{HbA} 1 \mathrm{c}$ and fetal anomalies

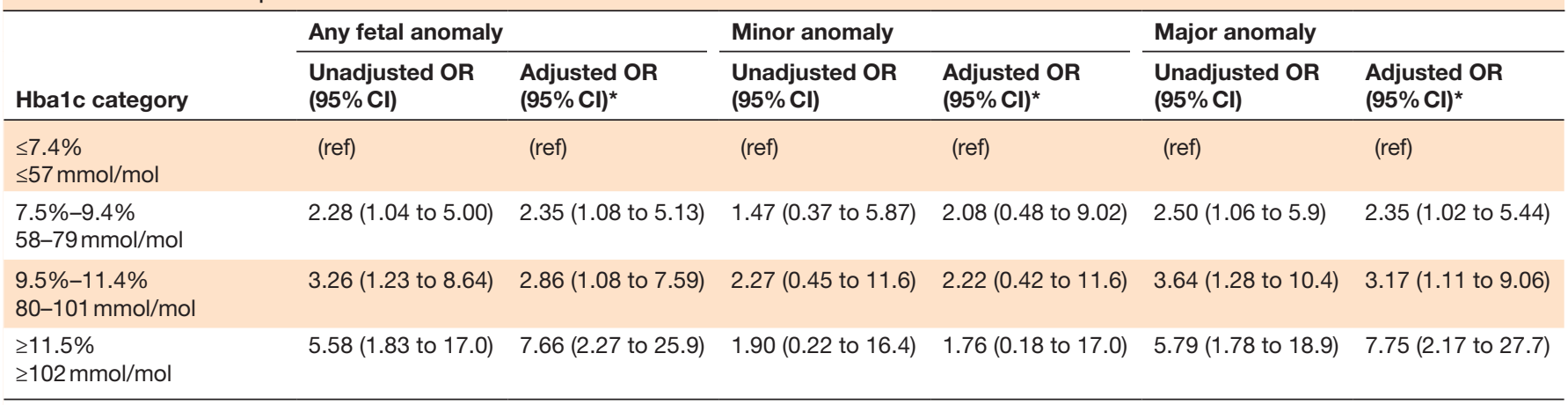


diabetes that is often missed are women who experienced gestational diabetes in prior pregnancies, ${ }^{37}$ approximately $25 \%-50 \%$ of whom will develop type 2 diabetes over 10 years. ${ }^{38}{ }^{39}$ Identifying women with undiagnosed diabetes prior to pregnancy might further decrease the incidence of congenital anomalies due to diabetes.

Major strengths of this study include the availability of 14 years of data from high-volume (over 11000 births per year) tertiary care center with a specialized diabetes in pregnancy program. The availability of multiple types of medical records allowed ascertainment of all women with pregestational diabetes regardless of pregnancy outcome and allowed for triangulation of outcomes from multiple sources, rather than relying on International Classification of Disease (ICD) 9 or ICD-10 codes found in administrative data, as used in most prior studies.

However, this study has several limitations. Only those anomalies detected antenatally or shortly after birth were identified, as there were no follow-up data for neonates after initial discharge from the delivery hospitalization, and many anomalies, particularly cardiac, are diagnosed later in childhood. Additionally, minor anomalies may not have been apparent in the initial newborn exams, limiting their ability to be captured. Even in the group with the best glycemic control (HbAlc $\leq 7.4 \%, \leq 57 \mathrm{mmol}$ / $\mathrm{mol}$ ), we found a higher rate of anomalies in than in prior studies. The overall anomaly rate in our cohort was nearly $10 \%$, compared with rates of $3 \%-4 \%$ in prior studies. ${ }^{726}$ This higher prevalence may reflect improved detection of anomalies with more advanced screening ultrasound technology and use of fetal echocardiograms. We may therefore be identifying more anomalies that may have negligible significance on a neonates' future health, such as a small ventricular septal defect. Alternatively, this higher rate may reflect a higher baseline rate of anomalies in this population. Despite the high birth volume of our institution, the sample size is relatively small, especially in the groups with the worst glycemic control, reflected by our large CIs.

In addition, as this study covers a long time period, there may have been changes to the management of diabetes in both pregnant and non-pregnant adults that may affect periconceptional HbAlc, including technologies such as insulin analogs, insulin pumps, continuous glucose monitors and other treatment practices such as the increased use of telehealth. However, the purpose of this study was not to describe temporal changes in diabetes management or the impact of such changes on glycemic control, but rather to evaluate the relationship of glycemic control on risk for congenital malformation. We are unable to control for all aspects of prenatal care and patient characteristics that may affect the likelihood of congenital malformations, such as folic acid intake, substance use, type of diabetes therapy and use of other medications such as ACE inhibitors. Thus, residual confounding may remain. As this is a retrospective study using existing data, $\mathrm{HbAlc}$ was not measured at a uniform point in time and is subject to inherent variability that would not occur in a prospective study with standardized timing. Finally, there may be selection bias in terms of which women with diabetes had periconception HbAlc testing; future work on expanding periconception care will be important for improving the health of pregnant women with diabetes and in order to reduce potential selection bias in this investigation.

\section{CONCLUSIONS}

In a diverse cohort of women with pregestational diabetes in the USA, higher periconception HbAlc was significantly associated with major and minor congenital fetal anomalies. The prevalence of anomalies was overall very high and supports the ongoing need for attention to reproductive life planning and glycemic control even in a changing population of individuals with pregestational diabetes. These findings have important clinical and public health implications in the counseling of pregnant women with diabetes, and most importantly, those women with diabetes presenting for care in the preconception period.

Contributors AMD, AS and LMY contributed to the study design. NB and AS contributed to the data acquisition. AMD and NB contributed to the statistical analysis. AMD, NB and LMY interpreted the data. AMD drafted the manuscript. LMY supervised the study. All authors contributed to the critical revision of the manuscript for important intellectual content. AMD is the guarantor of this work and, as such, had full access to all the data in this study and takes responsibility for the integrity of the data and the accuracy of the data analysis.

Funding LMY was supported by the NICHD K12 HD050121-11 at the time of this research. Research reported in this publication was supported, in part, by the National Institutes of Health's National Center for Advancing Translational Sciences, Grant Number UL1TR001422.

Disclaimer The content is solely the responsibility of the authors and does not necessarily represent the official views of the National Institutes of Health.

Competing interests None declared.

Patient consent for publication Not required.

Ethics approval The work presented in this paper was approved by the Northwestern University Institutional Review Board with a waiver of informed consent (\#STU00206821).

Provenance and peer review Not commissioned; externally peer reviewed.

Data availability statement No data are available. This study uses clinical data from Northwestern University. Per our Institutional Review Board approval, we cannot share data with individuals not listed on the protocol.

Open access This is an open access article distributed in accordance with the Creative Commons Attribution Non Commercial (CC BY-NC 4.0) license, which permits others to distribute, remix, adapt, build upon this work non-commercially, and license their derivative works on different terms, provided the original work is properly cited, appropriate credit is given, any changes made indicated, and the use is non-commercial. See: http://creativecommons.org/licenses/by-nc/4.0/.

ORCID iDs

Annie M Dude http://orcid.org/0000-0001-9619-7853

Lynn M Yee http://orcid.org/0000-0002-6274-0544

\section{REFERENCES}

1 Deputy NP, Kim SY, Conrey EJ, et al. Prevalence and changes in preexisting diabetes and gestational diabetes among women who had a live birth - United States, 2012-2016. MMWR Morb Mortal Wkly Rep 2018;67:1201-7

2 Hayes DK, Fan AZ, Smith RA. Trends in selected chronic conditions and behavioral risk factors among women of reproductive age, 
behavioral risk factor surveillance system, 2001-2009. Prev Chronic Dis 2011:8:A120.

3 Mills JL, Simpson JL, Driscoll SG, et al. Incidence of spontaneous abortion among normal women and insulin-dependent diabetic women whose pregnancies were identified within 21 days of conception. N Engl J Med 1988;319:1617-23.

4 Starikov R, Dudley D, Reddy UM. Stillbirth in the pregnancy complicated by diabetes. Curr Diab Rep 2015;15:11.

5 Ladfors L, Shaat N, Wiberg N, et al. Fetal overgrowth in women with type 1 and type 2 diabetes mellitus. PLoS One 2017;12:e0187917.

6 Callec R, Perdriolle-Galet E, Sery G-A, et al. Type 2 diabetes in pregnancy: rates of fetal malformations and level of preconception care. J Obstet Gynaecol 2014;34:648-9.

7 Greene MF, Hare JW, Cloherty JP, et al. First-Trimester hemoglobin A1 and risk for major malformation and spontaneous abortion in diabetic pregnancy. Teratology 1989;39:225-31.

8 Balsells M, García-Patterson A, Gich I, et al. Maternal and fetal outcome in women with type 2 versus type 1 diabetes mellitus: a systematic review and metaanalysis. J Clin Endocrinol Metab 2009;94:4284-91.

9 Ylinen K, Aula P, Stenman UH, et al. Risk of minor and major fetal malformations in diabetics with high haemoglobin A1c values in early pregnancy. Br Med J 1984;289:345-6.

10 Eriksen NB, Damm P, Mathiesen ER, et al. The prevalence of congenital malformations is still higher in pregnant women with pregestational diabetes despite near-normal HbA1c: a literature review. J Matern Fetal Neonatal Med 2019;32:1225-9.

11 Holmes LB. Current concepts in genetics. Congenital malformations. N Engl J Med 1976;295:204-7.

12 Tinker SC, Gilboa SM, Moore CA, et al. Specific birth defects in pregnancies of women with diabetes: National birth defects prevention study, 1997-2011. Am J Obstet Gynecol 2020;222:176. e1-176.e11.

13 Spector LG, Menk JS, Knight JH, et al. Trends in long-term mortality after congenital heart surgery. J Am Coll Cardiol 2018;71:2434-46.

14 Jovanovič L, Liang Y, Weng W, et al. Trends in the incidence of diabetes, its clinical sequelae, and associated costs in pregnancy. Diabetes Metab Res Rev 2015;31:707-16.

15 Peng TY, Ehrlich SF, Crites Y, et al. Trends and racial and ethnic disparities in the prevalence of pregestational type 1 and type 2 diabetes in northern California: 1996-2014. Am J Obstet Gynecol 2017:216:177.e1-177.e8.

16 Slot A, Eriksen NB, Ringholm L, et al. Congenital heart defects in offspring of women with type 2 diabetes - a systematic review. Dan Med J 2019;66:A5543.

17 Starikov R, Bohrer J, Goh W, et al. Hemoglobin A1c in pregestationa diabetic gravidas and the risk of congenital heart disease in the fetus. Pediatr Cardiol 2013;34:1716-22.

18 Liu S, Rouleau J, León JA, et al. Impact of pre-pregnancy diabetes mellitus on congenital anomalies, Canada, 2002-2012. Health Promot Chronic Dis Prev Can 2015;35:79-84.

19 Leirgul E, Brodwall K, Greve G, et al. Maternal diabetes, birth weight, and neonatal risk of congenital heart defects in Norway, 1994-2009. Obstet Gynecol 2016;128:1116-25.

20 Øyen N, Diaz LJ, Leirgul E, et al. Prepregnancy diabetes and offspring risk of congenital heart disease: a nationwide cohort study. Circulation 2016;133:2243-53.

21 Chou HH, Chiou MJ, Liang FW. Association of maternal chronic disease with risk of congenital heart diease in offspring. $\mathrm{CMJ}$ 2016;188:e438-46.

22 European Surveillance of Congenital Anomalies. EUROCAT guide 1.4 and reference documents. Available: https://eu-rd-platform.jrc.ec. europa.eu/sites/default/files/Full_Guide_1_4_version_28_DEC2018. pdf [Accessed 2 Mar 2021]
23 Van Regemorter N, Dodion J, Druart C, et al. Congenital malformations in 10,000 consecutive births in a university hospital: need for genetic counseling and prenatal diagnosis. $J$ Pediatr 1984:104:386-90.

24 Ludvigsson JF, Neovius M, Söderling J, et al. Periconception glycaemic control in women with type 1 diabetes and risk of major birth defects: population based cohort study in Sweden. BMJ 2018;362:k2638.

25 Lawrence JM, Contreras R, Chen W, et al. Trends in the prevalence of preexisting diabetes and gestational diabetes mellitus among a racially/ethnically diverse population of pregnant women, 19992005. Diabetes Care 2008;31:899-904.

26 Guerin A, Nisenbaum R, Ray JG. Use of maternal GHb concentration to estimate the risk of congenital anomalies in the offspring of women with prepregnancy diabetes. Diabetes Care 2007;30:1920-5.

27 Bell R, Glinianaia SV, Tennant PWG, et al. Peri-conception hyperglycaemia and nephropathy are associated with risk of congenital anomaly in women with pre-existing diabetes: a population-based cohort study. Diabetologia 201210.1007/s00125012-2455-y. [Epub ahead of print: 08 Feb 2012]

28 Persson M, Norman M, Hanson U. Obstetric and perinatal outcomes in type 1 diabetic pregnancies: a large, population-based study. Diabetes Care 2009;32:2005-9.

29 American Diabetes Association. 14. Management of diabetes in pregnancy: standards of medical care in diabetes-2019. Diabetes Care 2019;42:S165-72.

30 Wahabi HA, Alzeidan RA, Bawazeer GA, et al. Preconception care for diabetic women for improving maternal and fetal outcomes: a systematic review and meta-analysis. BMC Pregnancy Childbirth 2010;10:63

31 Chor J, Rankin K, Harwood B, et al. Unintended pregnancy and postpartum contraceptive use in women with and without chronic medical disease who experienced a live birth. Contraception 2011;84:57-63.

32 Schwarz EB, Postlethwaite D, Hung Y-Y, et al. Provision of contraceptive services to women with diabetes mellitus. J Gen Intern Med 2012;27:196-201.

33 Cyganek K, Hebda-Szydlo A, Katra B, et al. Glycemic control and selected pregnancy outcomes in type 1 diabetes women on continuous subcutaneous insulin infusion and multiple daily injections: the significance of pregnancy planning. Diabetes Technol Ther 2010;12:41-7.

34 Cheng D, Schwarz EB, Douglas E, et al. Unintended pregnancy and associated maternal preconception, prenatal and postpartum behaviors. Contraception 2009;79:194-8.

35 Peterson C, Grosse SD, Li R, et al. Preventable health and cost burden of adverse birth outcomes associated with pregestational diabetes in the United States. Am J Obstet Gynecol 2015;212:74. e1-74.e9.

36 Britton LE, Hussey JM, Crandell JL, et al. Racial/Ethnic disparities in diabetes diagnosis and glycemic control among women of reproductive age. J Womens Health 2018;27:1271-7.

37 Yarrington C, Zera C. Health systems approaches to diabetes screening and prevention in women with a history of gestational diabetes. Curr Diab Rep 2015;15:114.

38 Eades CE, Styles M, Leese GP, et al. Progression from gestational diabetes to type 2 diabetes in one region of Scotland: an observational follow-up study. BMC Pregnancy Childbirth 2015;15:11

39 Gabbe SG, Landon MB, Warren-Boulton E, et al. Promoting health after gestational diabetes: a national diabetes education program call to action. Obstet Gynecol 2012;119:171-6. 